\title{
Combined Effects of Prey Concentration and Photoperiod on Survival and Growth of Larval Sea Bream, Archosargus rhomboidalis (Sparidae)
}

\author{
C. E. Dowd and E. D. Houde \\ Rosenstiel School of Marine and Atmospheric Science, University of Miami, 4600 Rickenbacker Causeway, Miami, Florida \\ 33149, USA
}

\begin{abstract}
Effects of prey concentrations and photoperiods on survival and growth of larval sea bream Archosargus rhomboidalis (Sparidae) were determined in laboratory experiments. Larvae were reared from eggs to $16 \mathrm{~d}$ after hatching on copepod nauplii at $25,50,100$ or $500 \mathrm{l}^{-1}$ combined with photoperiods of 7,13 or $19 \mathrm{~h}$ light. Survival was highest at $13 \mathrm{~h}$ light duration and increased as the prey level was raised. Growth was best at $13 \mathrm{~h}$ light when prey concentrations were 100 or $500 \mathrm{l}^{-1}$, but was best at $19 \mathrm{~h}$ light when prey concentrations were 25 or $50 \mathrm{l}^{-1}$ At high prey levels the larvae survived and grew best at ambient light durations; at low prey levels they benefited in growth, but not in survival, from a longer than normal photoperiod.
\end{abstract}

\section{INTRODUCTION}

Year-class size in marine fishes is determined in large part by mortality during the larval stage (Hunter, 1976) when food availability is an important factor (Cushing, 1975). Effects of food availability on larval growth and survival have been examined in laboratory and field experiments (Lasker, 1975; Houde, 1978; Houde and Taniguchi, 1979). Because larval fishes are visual feeders and cannot feed at most night light levels (Blaxter, 1966, 1968a, 1968b), their growth and survival may be limited by the daylight hours available for feeding as well as by prey availability (Blaxter, 1966). In a laboratory study we have examined effects of photoperiod and prey concentration on growth and survival of larval sea bream Archosargus rhomboidalis.

Some aspects of the role of light in larval fish ecology have been investigated. The structure of the eye of larval plaice Pleuronectes platessa and sole Solea solea, larval responses to visual stimuli and the role of light in vertical migration were investigated by Blaxter (1968a, b, 1969, 1972, 1973, 1974). Light, its uses and role in successful larval fish culture have been reviewed in 'Marine Ecology', Volume III by Kinne (1977), and the responses of fishes to light, in 'Marine Ecology', Volume I by Blaxter (1970). The number of daylight hours required for adequate feeding by larval herring Clupea harengus, given the estimated food requirements and average prey concentration in the field, were estimated by Ivlev (1960) and Blaxter (1966). Laurence (1977), using data on the number of hours of light available and food requirements of larvae, predicted limiting prey concentrations for winter flounder Pseudopleuronectes americanus. Laboratory experiments to determine effects of light intensity and photoperiod on larval fish growth and survival were reported by Barahona-Fernandes (1979) on sea bass Dicentrarchus labrax and Kiyono and Hirano (in press) on black porgy Mylio macrocephalus. The effect of photoperiod on growth and survival of sole larvae was examined by Fuchs (1978).

Objectives of our research were (1) to examine the effect of length of photoperiod on growth and survival of larval Archosargus rhomboidalis, and (2) to determine whether required prey concentrations differed in relation to length of photoperiod.

\section{METHODS}

Fertilized eggs of Archosargus rhomboidalis (family Sparidae) were collected in 1-m diameter plankton nets in Biscayne Bay, Florida (USA) and stocked in 76-1 rectangular tanks at a density of $21^{-1}$. Rearing procedures were similar to those described by Houde (1978). Water temperatures were maintained at $26^{\circ} \mathrm{C} \pm 1 \mathrm{C}^{\circ}$ and phytoplankton blooms of Anacystis sp. and Chlorella sp. were added as a water conditioner. Vari- 
ous size fractions of live zooplankton from Biscayne Bay were used as food: larvae $<10 \mathrm{~d}$ old received the 53-110 $\mu \mathrm{m}$ fraction which consisted mainly of copepod nauplii and copepodites; those $>10 \mathrm{~d}$ old received the 110-280 $\mu \mathrm{m}$ fraction which was mostly copepodites. Prey concentrations were checked at least three times daily (Houde, 1978) and prey was added when necessary. To maintain water quality, $20 \%$ of the tank volumes were exchanged every other day.

Rearing tanks were placed in black plastic sheet enclosures to isolate tanks from incidental light. Rearing systems were exposed to controlled light-dark cycles. During the light phase of the cycle, fluorescent lights provided 2500-2800 lux at the water surface. This level is routinely used to culture fish larvae in our laboratory and is near the optimum level found by Kiyono and Hirano (in press) for rearing black porgy larvae.

Experiments were conducted during spring and fall 1979. Initially, 140 eggs were stocked in each experimental tank. Four prey concentrations, $25 \mathrm{l}^{-1}, 50 \mathrm{l}^{-1}$, $100 \mathrm{l}^{-1}$ and $500 \mathrm{l}^{-1}$ and three photoperiods, $7 \mathrm{~h}$ of light, $13 \mathrm{~h}$ and $19 \mathrm{~h}$, were tested. Three replicates were run at each prey density-photoperiod combination giving a total of 36 experiments. All experiments were run until larvae were $16 \mathrm{~d}$ old, or terminated earlier if all larvae died. At the end of an experiment survivors were measured and stored in $5 \%$ formalin. Later, preserved larvae from each experiment were dried at $70{ }^{\circ} \mathrm{C}$ for $24 \mathrm{~h}$ and mean dry weights were obtained.

The analysis of effects of food density and photoperiod on survival and growth of sea bream larvae was carried out in a two-way Analysis of Variance. Differences were considered significant at the $\alpha=0.05$ level. Because survivals were reported in percentages, data were arcsin transformed before the ANOVA was run. Missing values for data on mean lengths and mean weights (when there were no survivors) were treated using standard statistical procedures (Snedecor and Cochran, 1967). Weight data were transformed to $\log _{10}$ values to normalize their distribution and
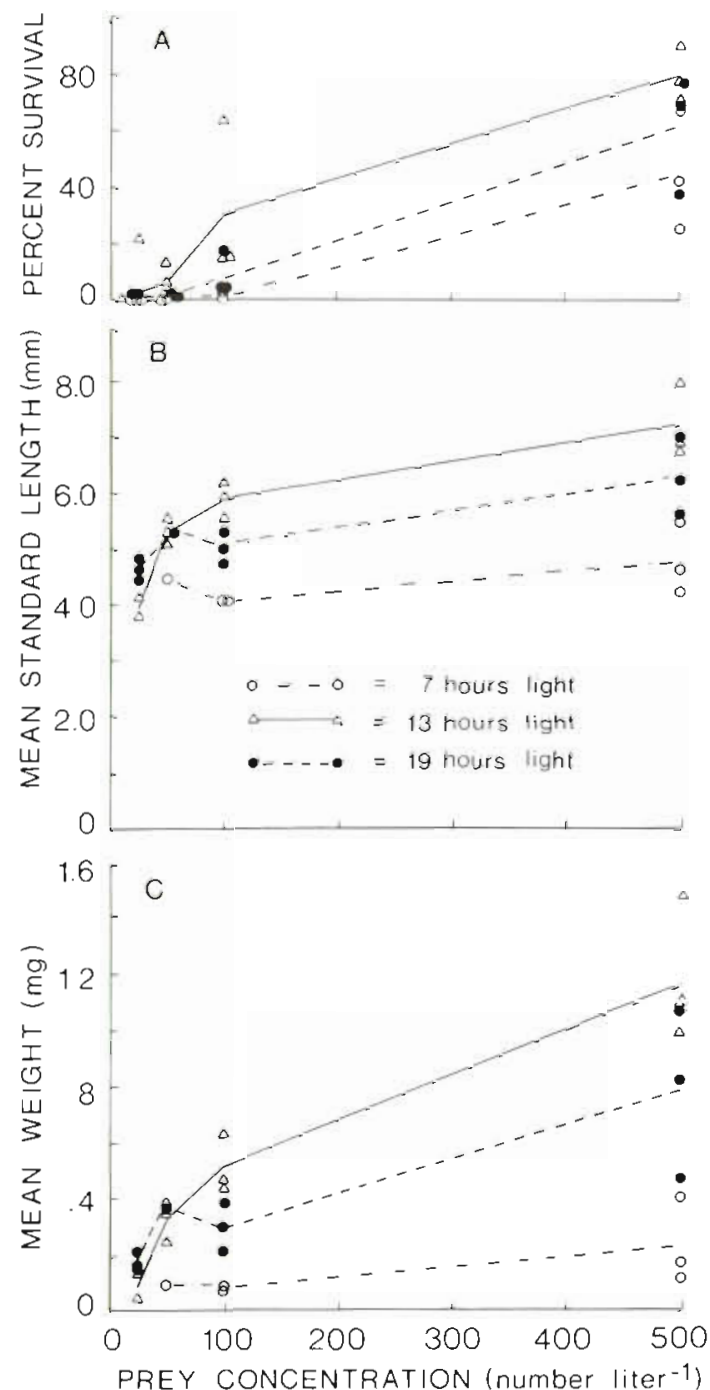

Fig. 1. Archosargus rhomboidalis. Survival, lengths and dry weights of larvae in relation to prey concentration for three photoperiods. Lines connect mean values for three replicates at each prey concentration-photoperiod combination

homogenize variances. When significant differences among means were shown by the ANOVA, a Newman-

Table 1. Archosargus rhomboidalis. Percent survival at $16 \mathrm{~d}$ after hatching of larvae in relation to light duration and prey concentration. Each entry represents the mean percent survival of three experiments; numbers in parentheses are standard errors of the mean

\begin{tabular}{|c|c|c|c|c|c|c|c|c|}
\hline \multirow{2}{*}{$\begin{array}{l}\text { Prey concentration } \\
\left.\text { (Number } \mathrm{l}^{-2}\right) \\
25\end{array}$} & \multicolumn{2}{|c|}{7} & \multicolumn{4}{|c|}{ Light duration (h) } & \multicolumn{2}{|c|}{ Mean } \\
\hline & 0 & & 7.62 & $(7.26)$ & 2.14 & $(0.41)$ & 3.25 & (2.39) \\
\hline 50 & 0.24 & $(0.24)$ & 7.62 & $(3.72)$ & 0.71 & $(0.71)$ & 2.86 & $(1.62)$ \\
\hline 100 & 1.67 & $(1.04)$ & 32.14 & $(16.07)$ & 9.05 & $(4.05)$ & 14.28 & (6.64) \\
\hline 500 & 45.96 & $(12.26)$ & 80.47 & $(5.44)$ & 61.91 & $(12.24)$ & 62.78 & (7.24) \\
\hline Meàn & 11.96 & $(6.48)$ & 31.96 & (9.83) & 18.45 & $(8.11)$ & & \\
\hline
\end{tabular}


Keuls multiple comparison test was run to determine which of the means differed significantly.

\section{RESULTS}

\section{Survival}

Both photoperiod and prey concentration affected survival significantly. No significant interaction occurred between these two factors. Highest mean survival at all prey concentrations occurred at $13 \mathrm{~h}$ light (Table 1). Percent survivals at both 7 und $19 \mathrm{~h}$ differed significantly from that at $13 \mathrm{~h}$ but not from each other. Mean percent survival over all prey levels at $13 \mathrm{~h}$ was 2.7 times higher than at $7 \mathrm{~h}$ and 1.7 times higher than that at $19 \mathrm{~h}$ light duration. Mean survival over all photoperiods was highest at $5001^{-1}$ prey concentration (Table 1). Survival rates did not differ significantly between the $25 \mathrm{l}^{-1}$ and $50 \mathrm{l}^{-1}$ prey levels but these rates were significantly lower than rates at 100 and $500 \mathrm{l}^{-1}$ prey levels. At each photoperiod, percent survival tended to increase as prey concentration increased; mean survival always was highest at $13 \mathrm{~h}$ light (Fig. 1).

\section{Growth}

Growth also was influenced by both prey concentration and photoperiod; there was no significant interaction effect between the two factors. Mean standard lengths were highest at $13 \mathrm{~h}$ light, intermediate at $19 \mathrm{~h}$ and least at $7 \mathrm{~h}$ (Table 2); standard lengths differed significantly among all three photoperiods. Mean standard length was highest at $5001^{-1}$ prey concentration. Standard lengths did not differ significantly at 50 and $100 \mathrm{l}^{-1}$ prey levels but lengths at those levels did differ from those at 25 and $500 \mathrm{l}^{-1}$ levels. For each photoperiod, mean standard lengths tended to increase as prey concentrations were raised (Fig. 1). At 100 and $500 \mathrm{l}^{-1}$ prey levels, mean lengths were highest at the $13 \mathrm{~h}$ light duration but at 25 and $50 \mathrm{l}^{-1}$ prey levels mean lengths were highest at $19 \mathrm{~h}$ light (Table 2).

Mean weights of survivors also were affected by photoperiod and prey concentrations (Table 3). The highest mean weight over all prey levels was observed at $13 \mathrm{~h}$ light duration; it did not differ significantly from that at $19 \mathrm{~h}$ but did differ from the $7 \mathrm{~h}$ mean. Highest mean weights were observed at the $500 \mathrm{I}^{-1}$ prey level. Mean weights at 50 and 100 prey $\mathrm{l}^{-1}$ did not

Table 2. Archosargus rhomboidalis. Mean standard lengths ( $\mathrm{mm}$ ) at $16 \mathrm{~d}$ after hatching of larvae in relation to light duration and prey concentration. Each entry represents the mean standard length of three replicates; numbers in parentheses are standard errors of the mean

\begin{tabular}{|c|c|c|c|c|c|c|c|c|}
\hline \multirow{2}{*}{$\begin{array}{l}\text { Prey concentration } \\
\text { (Number } \mathrm{I}^{-1} \text { ) } \\
25\end{array}$} & \multicolumn{8}{|c|}{ Light duration (h) } \\
\hline & & & 3.98 & $(0.18)$ & 4.66 & $(0.12)$ & 4.39 & $(0.19)$ \\
\hline 50 & 4.48 & • & 5.31 & $(0.13)$ & 5.33 & $\cdot$ & 5.15 & $(0.18)$ \\
\hline 100 & 4.07 & $(0.01)$ & 5.89 & $(0.18)$ & 5.03 & $(0.17)$ & 5.11 & $(0.28)$ \\
\hline 500 & 4.81 & $(0.38)$ & 7.19 & $(0.38)$ & 6.30 & $(0.39)$ & 6.10 & $(0.40)$ \\
\hline Mean & 4.51 & $(0.23)$ & 5.74 & $(0.36)$ & 5.33 & $(0.25)$ & & \\
\hline
\end{tabular}

Table 3. Archosargus rhomboidalis. Mean dry weights (mg) at $16 \mathrm{~d}$ after hatching of larvae in relation to light duration and prey concentration. Each entry represents the mean dry weight of three replicates; numbers in parentheses are standard errors of the mean

\begin{tabular}{|c|c|c|c|c|c|c|c|c|}
\hline \multirow{2}{*}{$\begin{array}{l}\text { Prey concentration } \\
\text { (Number } \mathrm{l}^{-1} \text { ) }\end{array}$} & \multicolumn{8}{|c|}{ Light duration (h) } \\
\hline & & & 0.098 & $(0.048)$ & 0.183 & $(0.017)$ & 0.149 & $(0.027)$ \\
\hline 50 & 0.104 & - & 0.329 & $(0.041)$ & 0.380 & ? & 0.294 & $(0.054)$ \\
\hline 100 & 0.093 & $(0.013)$ & 0.520 & $(0.063)$ & 0.305 & $(0.050)$ & 0.332 & $(0.068)$ \\
\hline 500 & 0.234 & $(0.089)$ & 1.150 & $(0.167)$ & 0.788 & $(0.170)$ & 0.724 & $(0.152)$ \\
\hline Mean & 0.166 & $(0.050)$ & 0.563 & $(0.129)$ & 0.421 & $(0.095)$ & & \\
\hline \multicolumn{9}{|c|}{$\begin{array}{l}\text { F value for light duration }=43.8(\mathrm{P}<.001) \text { for } 2,15 \text { degrees of freedom } \\
\text { F value for prey concentration }=27.4(\mathrm{P}<.001) \text { for } 3,15 \text { degrees of freedom } \\
\text { - Only } 1 \text { survivor }\end{array}$} \\
\hline
\end{tabular}


differ significantly from each other but did differ from both the 25 and 500 prey ${ }^{-1}$ levels. At all light durations, mean weight tended to increase as prey concentration rose (Fig. 1). Mean weights were highest at the $13 \mathrm{~h}$ light durations when prey concentrations were 100 and $500 \mathrm{I}^{-1}$ but were highest at $19 \mathrm{~h}$ light when prey concentrations were 25 and $50 \mathrm{I}^{-1}$.

\section{DISCUSSION}

Length of photoperiod significantly affected growth and survival of larval Archosargus rhomboidalis. Mean survival at each food concentration was always highest at the $13 \mathrm{~h}$ light duration and lowest at the $7 \mathrm{~h}$ duration. Growth at moderate to high prey levels was best at $13 \mathrm{~h}$ light. At the lowest prey levels tested, survivors reared at $19 \mathrm{~h}$ light grew fastest but survivorship was higher at $13 \mathrm{~h}$ light.

Archosargus rhomboidalis is a subtropical species which spawns in spring and fall when average daylength is between 12 and $13 \mathrm{~h}$. Observed survival and growth apparently reflected the adaptation of larvae to the prevailing photoperiod regime. At $7 \mathrm{~h}$ light, most larvae apparently did not have sufficient time to consume enough prey to gain the necessary energy for growth and survival. Even at the highest prey level used, survival was significantly lower at 7 h than at 13 or $19 \mathrm{~h}$ light durations. During the lighted portion of the day, larvae swam actively and their metabolic rates presumably were high, perhaps 2.5 times higher than those during the inactive dark period (Ware, 1975; Laurence, 1977). If the amount of food that can be processed by larvae in a 24 -h period is limited, larvae reared under longer than optimal light regimes may swim actively, expending energy, but consuming prey at decreased rates. Thus, metabolic demands might. increase significantly at long light durations causing less food energy to be available for growth and causing mortality of those individuals that were feeding at below average rates. This explanation could account for the lower growth and survival rates at $19 \mathrm{~h}$ light when prey levels were moderate or high compared to those at $13 \mathrm{~h}$. Only under poor feeding conditions, when the probability of a larva encountering sufficient food for maintenance and growth in $13 \mathrm{~h}$ light is low, might the benefit of additional hours to search for food outweigh the disadvantage of additional energy expenditure. At 25 and $50 \mathrm{l}^{-1}$ prey levels, A. rhomboidalis larvae did grow slightly faster at $19 \mathrm{~h}$ than at $13 \mathrm{~h}$ light, but survival remained best at $13 \mathrm{~h}$. The advantage gained by a few individuals, in terms of increased growth, did not confer an overall survival advantage to the larval population. At prey levels between 50 and $500 \mathrm{I}^{-1}$, which are usually present in
Biscayne Bay, Florida (Houde, 1978), where A. rhomboidalis is common, the larvae seem to be well adapted to survive and grow best under the prevalent photoperiod.

Survival of sea bass larvae (Barahona-Fernandes, 1979) and black porgy larvae (Kiyono and Hirano, in press) was best at the same light duration as in our experiments (i. e, 12-13 h light). Photoperiod did not affect survival of sole larvae (Fuchs, 1978). Highest growth, however, in those three investigations was obtained at 18-24 h light. Although the reason for this difference has not been determined, it may be related to the type and concentration of prey used in the experiments. Fuchs, Barahona-Fernandes and Kiyono and Hirano reared larvae on rotifers, Brachionus sp., and brine shrimp Artemia salina, while larvae in our experiments were reared on wild plankton. Taniguchi (in press) has shown that spotted seatrout Cynoscion nebulosus larvae reared on brine shrimp and rotifers have lower growth rates than larvae reared on wild plankton. Larvae in the experiments of Barahona-Fernandes (1979) and Fuchs (1978) were reared at high prey levels, up to $7.5 \mathrm{ml}^{-1}$. Exact prey levels were not given by Kiyono and Hirano (in press). In our experiments only larvae reared at low prey levels obtained their best growth at $19 \mathrm{~h}$ light. It appears that when either prey quality or prey level is low, longer photoperiods can benefit larval growth.

For the subtropical Archosargus rhomboidalis, daylight, beyond that normally present, did not benefit the larvae when prey levels were near those usually found in its environment. Larvae of species from more temperate latitudes may be subject to quite different light regimes, with daylength changing greatly as seasons progress. Under those conditions the interaction between photoperiod and prey concentration could be very significant as Ivlev (1960), Blaxter (1966) and Laurence (1977) have suggested. The timing of spawning could be critical, both to insure that larvae are produced when prey levels are adequate and also to insure that larvae have sufficient daylight hours to consume a ration that will provide enough energy for growth and survivail. It is possible that for those temperate species with relatively long spawning seasons, critical prey concentration may not be constant but may change as the season progresses, dependent on the hours of light that are available for larvae to feed.

\section{LITERATURE CITED}

Barahona-Fernandes, M. H. (1979). Some effects of light intensity and photoperiod on the sea bass larvae (Dicentrachus labrax [L.]) reared at the Centre Oceanologique de Bretagne. Aquaculture 17: 311-321 
Blaxter, J. H. S. (1966). The effect of light intensity on the feeding ecology of herring. In: Bainbridge, R, Evans, G. C., Rackham, O. (eds) Light as an ecological factor. Blackwell Scientific Publications, Oxford, pp. 393-409

Blaxter, J. H. S. (1968a). Visual thresholds and spectral sensitivity of herring larvae. J. exp. Biol. 48: 39-53

Blaxter, J. H. S. (1968b). Light intensity, vision and feeding in young plaice. J. exp. mar. Biol. Ecol. 2: 293-307

Blaxter, J. H. S. (1969). Visual thresholds and spectral sensitivity of flatfish larvae. J. exp. Biol. 51: 221-230

Blaxter, J. H. S. (1970). Light. Animals. Fishes. In: Kinne, O. (ed.) Marine ecology, Vol. I, Environmental factors, Part I. Wiley, London, pp. 213-320

Blaxter, J. H. S. (1972). Brightness discrimination in larvae of plaice and sole. J. exp. Biol. 57: 693-700

Blaxter, J. H. S. (1973). Monitoring the vertical movements and light responses of herring and plaice larvae. J. mar. biol. Ass. U. K. 53: 635-647

Blaxter, J. H. S. (1974). The role of light in the vertical migration of fish - a review. In: Evans, G. C., Bainbridge, R., Rackham, O. (eds) Light as an ecological factor: II. Blackwell Scientific Publications, Oxford, pp. 189-210

Cushing, D. H. (1975). Marine ecology and fisheries, Cambridge University Press, Cambridge

Fuchs, J. (1978). Influence de la photoperiode sur la croissance et la survie de la larve et du juvenile de sole (Solea solea) en elevage. Aquaculture 15: 63-74

Houde, E. D. (1978). Critical food concentrations for larvae of three species of subtropical marine fishes. Bull. mar. sci. 28: 395-411

Houde, E. D., Taniguchi, A. K. (1979). Laboratory culture of marine fish larvae and their role in marine environmental research. In: Jacoff, F. S. (ed.) Advances in marine environmental research. Proceedings of a Symposium. Environ. Res. Lab., U. S. Environmental Protection Agency, Narragansett, R. I. Ref. No. EPA-600/9-79-035
Hunter, J. R. (ed.) (1976). Report of a colloquium on larval fish mortality studies and their relation to fishery research, January 1975. NOAA Tech. Res. NMFS CIRC-395

Ivlev, V S. (1960). On the utilization of food by planktophage fishes. Bull. Math. Biophys. 22: 371-389

Kinne, O. (1977). Cultivation of animals. Research cultivation In: Kinne, O. (ed.) Marine ecology, Vol. III, Cultivation, Part 2. Wiley, Chichester, pp. 579-1293

Kiyono, M., Hirano, R. (in press). Effects of light on the feeding and growth of black porgy, Mylio macrocephalus (Basilewsky), postlarvae and juveniles. In: Lasker, R., Sherman, K. (eds) Early life history of fish. II. A second international symposium, held in Woods Hole, 2-5 April 1979. Rapp. P-v. Reun. Cons. Int. Explor. Mer 178

Lasker, R. (1975). Field criteria for survival of anchovy larvae: the relation between inshore chlorophyll maximum layers and successful first feeding. Fish. Bull. U. S. 73: 453-462

Laurence, G. C. (1977). A bioenergetic model for the analysis of feeding and survival potential of winter flounder, Pseudopleuronectes americanus, larvae during the period from hatching to metamorphosis. Fish. Bull. U. S, 75: $529-546$

Snedecor, G. W., Cochran, W. G. (1967). Statistical methods, 6th ed., Iowa State University Press, Ames

Taniguchi, A. K. (in press). Survival and growth of spotted seatrout (Cynoscion nebulosus) larvae in relation to temperature, prey abundance and stocking densities. In: Lasker, R., Sherman, K. (eds) Early life history of fish. II. A Second International Symposium, held in Woods Hole, 2-5 April 1979. Rapp. P-v. Réun. Cons. Int. Explor. Mer 178

Ware, D. M. (1975). Growth, metabolism and optimal swimming speed of a pelagic fish. J. Fish Res. Bd Can. 32: $33-41$ 